\title{
Recurrent rhabdomyolysis in a child. Case presentation
}

\author{
Asst. Prof. Sabahattin Ertuğrul ${ }^{a}$, Asst. Prof. Illyas Yolbaşs ${ }^{a}$, Asst. Prof. Fesih Aktar ${ }^{a}$, Kamil Yllmaz, M.D. ${ }^{b}$ and \\ Asst. Prof. Recep Tekin ${ }^{c}$
}

\begin{abstract}
Viral myositis associated with infections rarely may cause rhabdomyolysis. There is no any pediatric case with severe recurrent rhabdomyolysis triggered by infections in the literature. We reported a two-year-old boy who washospitalized three times due to severe rhabdomyolysis associated with viral myositis in the winter months. This is the first child case presentation with severe rhabdomyolysis triggered by infections. Prednisolone and intravenous immunoglobulin treatments were ineffective in this case.

Key words: rhabdomyolysis acute recurrent, infection, respiratory syncytial virus, pediatrics.
\end{abstract}

http://dx.doi.org/10.5546/aap.2016.eng.e192

\section{INTRODUCTION}

Viral myositis associated with infections such as respiratory syncytial virus, adenovirus, herpes simplex virus, Epstein-Barr virus, cytomegalovirus, mycoplasma and rotavirus rarely may cause rhabdomyolysis. ${ }^{1}$ In addition, trauma, severe exercise, drug reactions, metabolic disorders and status epilepticus cause rhabdomyolysis. Rhabdomyolysis is characterized with sudden muscle pain, inability to walk or difficulty in walking and elevated serum creatine phosphokinase (CPK). Clinical and laboratory finding rare resolved spontaneously within one week. ${ }^{1-3}$ Due to the clinical findings of rhabdomyolysis, differential diagnosis should be made with pyomyositis, muscular dystrophy, Guillain-Barre syndrome, transverse myelitis, meningitis and other diseases

a. Department of Pediatrics, Dicle University School of Medicine, Diyarbakir, Turkey.

b. Department of Pediatrics, Diyarbakir Children's Hospital, Diyarbakir, Turkey.

c. Department of Infectious Disease and Clinical Microbiology, Dicle University School of Medicine, Diyarbakir, Turkey.

E-mail address:

Asst.Prof. Fesih Aktar: fesihaktar@yahoo.com

Funding: None.

Conflict of interest: None.

Received: 10-19-2015

Accepted: 12-14-2015 such as postinfectious cerebellitis. ${ }^{4}$ In case of rhabdomyolysis, acute necrosis of skeletal muscle fibers and the resulting blend into the extracellular environment of the cell content may cause severe acute renal failure.., 6

However, many clinicians may fail to recognize rhabdomyolysis as an important complication associated with viral myositis. Recently, several cases of severe rhabdomyolysis associated with viral myositis were reported. ${ }^{5} \mathrm{We}$ did not find a child case with severe recurrent rhabdomyolysis associated with viral myositis in the literature. We aimed to present the clinical findings of the first pediatric case with severe recurrent rhabdomyolysis triggered by infections.

\section{CASE REPORT}

Two-year-old boy without any significant medical history and use of drugs (such as antihistamines) who were hospitalized three times with a 1-2 months interval due to severe rhabdomyolysis triggered by infections during the autumn.

The patient was refered by his pediatrician due to diarrhea for 10 days in the first oportunity and due to sore throath with fever in the two posterior ocassions. In the three episodes the patient presented widespread muscle pain and weakness in upper and lower extremity and neck muscles, and inability to walk and to remain in the standing position. White blood cell count, hemoglobin level and platelet cound were within normal range in the three hospitalizations. Downey cells in peripheral blood smears were studied but not identified in the three episodes.

During the first hospitalization chest X-ray and hepatitis marker, TORCH, ANA, anti-ds DNA, HIV test, electrocardiography, electromyography, CNS computed tomography and cerebro spinal fluid tests were observed normal. Respiratory syncytial virus test was not performed because it was not available at our hospital. No pathogen was isolated from blood, urine and stool cultures. Also Salmonella typhoid $\mathrm{O}$ and $\mathrm{H}$ antigen were found negative.

During the second hospitalization no abnormal findings were observed at tandemmass spectrometry, organic acid profile in 
urine, plasma aminoacids, muscle biopsy and other metabolic tests for metabolic myopathies including glycogenolysis disorders of lipid metabolism, krebs cycle, and the purine metabolism. Respiratory syncytial virus was identified by ELISA in nasopharingeal secretion sample.

$\mathrm{CPK}$, lactate dehydrogenase (LDH), aspartate aminotransferase (AST), alanine aminotransferase (ALT) levels were high at the $1^{\text {th }}$ day of hospitalizations and went down to normal values at the $7^{\text {th }}$ day of hospitalizations (Table 1).

The patient received conservative treatments such as intense volume repletion, followed by administration of diuretics (Furosemide) during the three admissions. Once diuresis was established, sodium bicarbonate was used to alkalize the urine. Prednisolone and intravenous immunoglobulin were also administered during the first hospitalization considering symptoms of severe rhabdomyolysis. In the three episodes the patient was completely recovered at day $7^{\text {th }}$.

\section{DISCUSSION}

There are a few cases with recurrent myositis associated with infections such as mycoplasma and hepatitis A infection. ${ }^{7,8}$ However, there is no pediatric case with severe recurrent rhabdomyolysis associated with infections in the literature. Our case is the first case with severe recurrent rhabdomyolysis associated with in fections. Patients with metabolic myopathies such as fatty acid oxidative disorders may have symptoms triggered by infections or other states of metabolic stress. ${ }^{7}$ Our patient had no histochemical evidence of any metabolic myopathy or metabolic diseases.

Previous studies reported that the prodromal period of viral myositis are seen between 2-31 days. ${ }^{4}$ In the largest series of pediatric rhabdomyolysis, Mannix et al. Reported that viral myositis was the most frequent cause, accounting for $38 \%$ of cases and in particular during the first decade of life. ${ }^{9}$ Influenza types $A$ and B, HIV, enteroviruses, Epstein-Barrvirus, cytomegalovirus, adenovirus, herpes simplex and varicella virus are the common viruses associated with rhabdomyolysis. ${ }^{5}$ In our case respiratory syncytial virus was associated with rhabdomyolysis and prodromal period was seen between 6-10 days.

Due to non-specific clinical and laboratory findings, viral myositis can be confused with other diseases. ${ }^{4}$ Raja Jee et al. Reported that $27.5 \%$ leukopenia, $40 \%$ thrombocytopenia and $70 \%$ high level ALT and AST were observed in patients with viralmyositis. ${ }^{1}$ Our case also had high level CPK, LDH, AST and ALT, also we made a differential diagnosis between polymyositis, metabolic diseases, muscular dystrophy, GuillainBarre syndrome, transverse myelitis and meningitis.

TABLE 1. Laboratory parameters of the patient due to days of hospitalization

\begin{tabular}{|c|c|c|c|c|c|c|c|c|c|c|}
\hline & $\begin{array}{c}\text { CPK } \\
(\mathrm{IU} / \mathrm{L})\end{array}$ & $\begin{array}{c}\text { ALT } \\
\text { (IU/L) }\end{array}$ & $\begin{array}{l}\text { AST } \\
(\mathrm{IU} / \mathrm{L})\end{array}$ & $\begin{array}{l}\text { LDH } \\
\text { (IU/L) }\end{array}$ & $\begin{array}{c}\text { BUN } \\
(\mathrm{mg} / \mathrm{dL})\end{array}$ & $\begin{array}{c}\mathrm{Cr} \\
(\mathrm{mg} / \mathrm{dL}) \\
\end{array}$ & $\begin{array}{c}\mathbf{N a} \\
(\mathrm{mEg} / \mathrm{L})\end{array}$ & $\begin{array}{c}\mathbf{K} \\
(\mathrm{mEg} / \mathrm{L}) \\
\end{array}$ & $\begin{array}{c}\mathrm{Ca} \\
(\mathrm{mg} / \mathrm{dL})\end{array}$ & $\begin{array}{c}\mathbf{P} \\
(\mathrm{mg} / \mathrm{dL}) \\
\end{array}$ \\
\hline \multicolumn{11}{|c|}{ First hospitalization } \\
\hline First day & 55000 & 450 & 3427 & $>1995$ & 8 & 0.34 & 138 & 4.3 & 9.7 & 4.4 \\
\hline Third day & 32000 & 1032 & 1253 & $>1995$ & 18 & 0.37 & 136 & 4.4 & 9.3 & 4.5 \\
\hline Seventh day & 1599 & 374 & 118 & 1847 & 12 & 0.36 & 137 & 4.1 & 9.9 & 4.4 \\
\hline \multicolumn{11}{|c|}{ Second hospitalization } \\
\hline First day & $>42670$ & 1198 & 4065 & $>1995$ & 12 & 0.39 & 137 & 4.3 & 9.8 & 4.5 \\
\hline Third day & 29000 & 810 & 869 & $>1995$ & 9 & 0.34 & 138 & 3.7 & 9.1 & 4.6 \\
\hline Seventh day & 2222 & 481 & 180 & $>1995$ & 16 & 0.41 & 138 & 4 & 10 & 6.3 \\
\hline \multicolumn{11}{|c|}{ Third hospitalization } \\
\hline First day & 45600 & 1120 & 3785 & $>1995$ & 18 & 0.33 & 136 & 4.1 & 9.3 & 4.1 \\
\hline Third day & 27500 & 728 & 618 & $>1995$ & 12 & 0.35 & 134 & 3.8 & 9.4 & 4.6 \\
\hline Seventh day & 978 & 376 & 152 & 1245 & 14 & 0.37 & 137 & 4.2 & 9.7 & 4.4 \\
\hline
\end{tabular}

*Serum creatinine phosphokinase (CPK, normal range; 22-200 IU/L), alanine aminotransferase (ALT, normal range; 10-60 IU/L), aspartate aminotransferase (AST, normal range; 10-55 IU/L), lactate dehydrogenase (LDH, normal range; $425-975$ IU/L), blood urea nitrogen (BUN, normal range; $3.4-7 \mathrm{mg} / \mathrm{dL})$, creatinine $(\mathrm{Cr}$, normal range; 0.3-0.7 mg/dL), Sodium (Na, normal range; 135-145 mEg/L), potassium (K, normal range; 3.4-4.7 mEg/L), Calcium (Ca, normal range; 8.6-10.6 mg/dL), phosphorus (P, normal range; 4.5-5.5 mg/dL). 
Treatment of rhabdomyolysis associated with infections has not been well studied, and what studies are present do not reveal that any one specific treatment leads to a significant difference in outcome. Mostly clinical improvement of viral myositis began in the 24-36 hours of treatment. ${ }^{4}$ Management is based on treating the underlying cause, preventing rhabdomyolysis in high-risk groups, using intensive fluid resuscitation, administering diuretics and sodium bicarbonate. ${ }^{10,11}$ Prednisolone and intravenous immunoglobulinare other treatment options. ${ }^{12} \mathrm{We}$ used fluid resuscitation, administering diuretics and sodium bicarbonate in the all hospitalization of our case. We also used prednisolone and intravenous immunoglobulin in the first hospitalization ofo ur patient. But recovery speed was the same in the all hospitalization. This case report shows that this patient was not benefit with prednisolone and IV immunoglobulin treatment.

In conclusion, we describe an unusual case of severe recurrent rhabdomyolysis associated with infections. This unusual case may further add to the understanding of recurrent rhabdomyolysis with infections. Determination of prednisolone and intravenous immunoglobulinin effectiveness in the treatment of rhabdomyolysis associated with infections require further research.

\section{REFERENCES}

1. RajajeeS, EzhilarasiS, Rajarajan K. Benign acute childhood myositis. Indian J Pediatr 2005;72(5):399-400.

2. Hu JJ, Kao CL, Lee PI, Chen CM, et al. Clinical features of influenza $A$ and $B$ in children and association with myositis. J Microbiol Immunol Infect 2004;37(2):95-8.

3. Mackay MT, Kornberg AJ, Shield LK, Dennett X. Benign acute childhood myositis: laboratory and clinical features. Neurology 1999;53(9):2127-31.

4. Saltık S, Surucu M, Ozdemir O. Benign childhood acute myositis: clinical and laboratory findings of 15 cases. Turk Pediatr Ars 2012;47(1):52-5.

5. Singh U, Scheld WM. Infectious etiologies of rhabdomyolysis: three case reports and review. Clin Infect Dis 1996;22(4):642-9.

6. Beetham R. Biochemical investigation of suspected rhabdomyolysis. Ann Clin Biochem 2000;37(Pt 5):581-7.

7. Wong SH, Lecky BR, Hart IJ, Crooks D, et al. Recurrent myositis triggered by infections: a case report. J Med Case Rep 2008;2:344.

8. Spillane K, Chesner IM. Recurrent myositis with infection. Postgrad Med J 1990;66(782):1087.

9. Mannix R, Tan ML, Wright R, Baskin M. Acute pediatric rhabdomyolysis: causes and rates of renal failure. Pediatrics 2006;118(5):2119-25.

10. Wu CT, Hsia SH, Huang JL. Influenza B-associated rhabdomyolysis in Taiwanese children. Acta Paediatr 2010;99(11):1701-4.

11. Chen CY, Lin YR, Zhao LL, Yang WC, etal.Clinical spectrum of rhabdomyolysis presented to pediatric emergency department. BMC Pediatr 2013;13:134.

12. Ishiwada N, Takada N, Okunushi T, Hishiki H, et al. Rhabdomyolysis associated with influenza A/H1N1 2009 infection in a pediatric patient. Pediatr Int 2012;54(5):703-5. 